\title{
Besedotvorje predmetnopomenskih besed v Bohoričevi slovnici Zimske urice proste
}

\author{
Irena STRAMLjiČ BreZnik \\ Univerza v Mariboru, Filozofska fakulteta, Koroška cesta 160, \\ SI-2000 Maribor, irena.stramljic@uni-mb.si
}

\begin{abstract}
Prispevek predstavlja besedotvorje predmetnopomenskih besed v prvi slovenski slovnici, ki jo je napisal Adam Bohorič. Kaže na njegovo sposobnost kategoriziranja besedotvornih prvin, ki so bile opazne $\mathrm{v}$ slovenskem govorjenem in/ali pisanem jeziku 16. stoletja, in sicer ob latinski jezikovnosistemski predlogi.

This article takes into account word-formation of the most typical meaningful word categories in the first Slovene Grammar Book written by Adam Bohorič. It examines his tendency to describe and classify word-formation elements typical and present in spoken and/ or written Slovene language of the $16^{\text {th }}$ century, despite his Latin training.
\end{abstract}

Ključne besede: Bohoričeva slovnica, besedotvorne kategorije, besedotvorna obrazila, predmetnopomenske besedne vrste

Key words: The Bohorič grammar, word forming categories, word forming affixes, root words, word classes

0 Bohoričeva slovnica je bila predmet številnih samostojnih razprav, ocen in zbornikov, nazadnje ji je bil odmerjen obsežen del monografije Kozme Ahačiča (2007: 69-211), ki navaja zelo natančen popis njenih obravnav (Ahačič 2007: 72-80) tako z jezikoslovnega kot literarnozgodovinskega vidika. Avtor v svoji monografiji tudi poglobljeno analizira in primerja posamezne dele Bohoričeve slovnice glede na vpliv takratnih latinskih slovnic ter posledično kompetentno ocenjuje Bohoričevo izvirnost. Prav zato se na tem mestu ne bomo ustavljali niti pri naštevanju niti pri predstavljanju tega številnega seznama bibliografskih enot, ampak se usmerili na pregled zgolj tistih del, ki se posredno ali neposredno dotikajo naslova tega prispevka, $\mathrm{tj}$. besedotvorne problematike. 
Iskanje ustreznih razprav s ključnima besedama besedotvorje in Bohorič po Cobbisovi podatkovni bazi z nič zadetki je bilo v začetku vsekakor spodbudno, pa vendar za kritičnega raziskovalca premalo prepričljivo za sklep, da se z besedotvorjem v Bohoričevi slovnici ni še podrobneje ukvarjal nihče.

Izbor in pregled relevantne literature je pokazal na dvoje: a) besedotvorje so omenjali razpravljalci M. Orožen (1971: 196-197), R. Kolarič (1971: 49-50), J. Toporišič (1984: 190) in K. Ahačič (2007: 122, 132-135; 143, 145; 157; b) omembe so bile pri prvih treh razpravljalcih dejansko bežne, pri zadnjem razpravljalcu pa primerjalne narave glede na Melanchtonovo in druge sočasne latinsko pisane slovnice ljudskih jezikov.

1.0 Preden preidemo na podrobnejšo predstavitev tega dela Bohoričeve slovnice, je zato nujno pregledati dvoje, kako in koliko je bilo besedotvorje vendarle omenjeno v navedenih razpravah.

1.1 Martina Orožen (1971) navaja, da je jezikovna snov, kot znano, razdeljena na tri dele: (1) DE ORTHOGRAPHIA (črkopis z zametki glasoslovja ter pravopisna navodila za rabo ločil); (2) DE ETYMOLOGIA (razmeroma natančno oblikoslovje z značilnostmi besedotvorja) in (3) DE SYNTAXI (pravila o zgradbi in rabi možnih sintaktičnih, celo stilističnih shem).

Ker se je v temeljnih obrisih in značilnostih ustavila ob vsakem od treh poglavij, je razumljivo, da je pri oblikoslovju opozorila tudi na tam pridruženo besedotvorje, in sicer najprej za imena (Orožen 1971: 196):

V poglavjih De Species ponazarja osnovne besedotvorne principe v slovenščini. Najbolj je opazil deminutivno tvorbo ter izpeljavo pridevnikov iz lastnih imen: kojn-kojnizhik; sob-sobec; Pfizh-pfizhiza, pfizhka; Lublanzhizh-Lublanzhiza, Terfhazhki itd.

\section{Podobno tudi pri obravnavi glagola (Orožen 1971: 197):}

Zanimivi sta še dve kategoriji: Figvra in Species, ki se v nekem smislu dopolnjujeta. Prva nakazuje slovenske možnosti za glagolsko izpeljavo glede na predpono

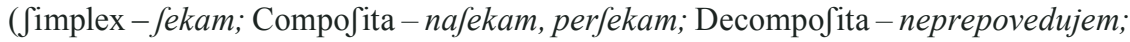
povedujem $=$ freqventatiuum a povejm), druga pa semantično skupino glagolov, kjer se odražajo zakonitosti slovenskega aspekta glede na premeno glagolske pripone; delno so te posebnosti še posebej leksikalno razložene v Derivativa vel Inchoativa, vt: sazhnem goreti (Je vname) fe sashiga vel sazhne vel perhaia /.../.

1.2 Tudi Kolarič (1971: 29-87) je v obsežni študiji zelo natančno predstavil vse tri strukturne dele Bohoričeve slovnice. Za vsebino prispevka je zanimiv osrednji del, imenovan Etimologija, ki ga Kolarič poimenuje Morfologija, saj je Bohorič v njem razpravljal o oblikah in slovničnih lastnostih besednih vrst.

Besedotvorna problematika je deloma zajeta že pri navajanju končnic po spolih pridevnika, saj Bohorič navaja, da se tudi samostalniki delajo s končnicami za spole tako, da so feminina na -a (kojn: kojnka; lev: levinja). Kolarič je celo mnenja, da je zgled kojnka skoraj zagotovo Bohoričeva novotvorjenka, v 
Pleteršnikovem slovarju (1894-1895) je namreč mogoče najti to besedo samo v pomenu 'vrsta smokve'.

Zanimivo je, da tudi Kolarič (1971: 44) ne opiše sicer kratkega poglavja z naslovom Figura, marveč ga zgolj omeni: »Es folgt der schon erwähnte kurze Abschnitt 'Figura'.«

Pri samostalniku pa se nasprotno kot pri pridevniku zelo natnačno razpiše o poglavju DE SPECIES (von der Wortbildung). Zanimiva je Kolaričeva opazka o Bohoričevi obravnavi besedotvorja: »Interessant sind Bohoričs Erwägungen über die Wortbildung (inwieweit sie volkstümlich ist, bleibt dahingestellt). « ${ }^{1}$

Podrobno je navedel vse Bohoričeve skupine: vrstne pridevnike na -ski (1. Patronymika) in svojilne na -ov (2. Possessiva), manjšalnice (3. Diminutiva) s tipičnimi obrazili za vse tri spole, posebno skupino tvorijo (4. Denominativa), kjer obravnava tvorbo pridevnikov in pridevniško rabljenih števnikov v osmih skupinah: 1. Materiam Jignificantia, 2. Habitum (Eigentümlichkeiten) Jignificantia, 3. Cupiditatem (Begierde, Leidenschaft) denotatia, 4. Copiam

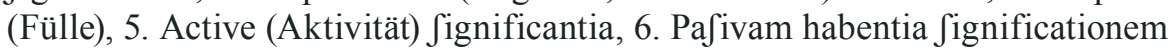
(Passive Bedeutung augedrückt), 7. Loca arborum (Gelände, wo Bäume wachsen), 8. Receptacula rerum (Behälter für Sachen). Ocena Kolariča (1971: 81) je zanimiva zlasti v delu, ko poudarja, da je vrednotenje slovnice $\mathrm{z}$ vidika slovenskega slovničnega sistema, ki ga je Bohorič uravnal po latinskem, v celoti zgrešeno, saj je treba njegovo slovnico vrednotiti z vidika sočasne latinske, grške, nemške slovniške tradicije 16. stoletja. Upoštevati je namreč treba, da Bohorič takrat ni imel pri roki nobene slovanske slovnice, po kateri bi se lahko zgledoval.

1.3 Tudi Toporišič (1984: 190) je izpostavil tipično zgradbenost Bohoričeve slovnice s posebnim poudrakom na poglavju Etimologija, ki združuje oblikoslovje (z besedotvorjem), ker se je v svoji razpravi omejil zgolj na oblikoslovje. Posebej je poudaril (Toporišič 1984: 190-191):

Uvodoma naj pripomnimo še, da v svojo obravnavo iz Bohoričeve Etimologije nismo zajeli besedoslovne, zlasti besedotvorne problemtike, kakor jo pri imenu predstavlja npr. Bohoričevo razpravljanje o liku (figuri): preprost (simplex) pravizhen - zložen (composita) nepravizhen - izzloženski (decomposita) nepravizhnoft (43), ali tvorjenost (De species): podstavno (primitivum) kojn - izpeljano (derivativum) kojnizhik, čemur nato sledijo primeri za očetna imena (Tershazhki), svojilnost (Shairerjou), manjšalnost (krajlizh), izimensko snovnost (Shelesen), opravljenost/opremljenost (obut/rogat), željnost (vinu vdan), obilnost (kamenit), prizadevnost (vuzhliv), netvornost (nenavidliv), združbo drevja (verbje ali verbifhzhe), vsebnik (perniza), zatem še tvorba števnikov (69-78), za katere pravi (69), da tudi gredo k izimenskim besedam.

1.4 Na podlagi podrobne primerjave Bohoričeve slovnice s takrat sočasno latinsko pisanimi slovnicami ljudskih jezikov (italijanskega, španskega, francoskega, češkega, portugalskega, valižanskega, poljskega, nemškega, holandskega) - nekatere med njimi so bile poleg Melanchtonove Bohoriču prav tako

\footnotetext{
${ }^{1}$ »Zanimive so Bohoričev ugotovitve o besedotvorju, čeprav so najbrž poljudne.»
} 
znane - je Kozma Ahačič (Ahačič 2007: 79) natančno predstavil Bohoričevo izvirnost posameznih delov poglavij in navajanje primerov tvorjenk, za katere ni mogoče najti vzporednic $\mathrm{v}$ predlogah.

Hkrati pa je kritično ocenil tudi Toporišičev (1987) prevod Bohoričeve slovnice v slovenščino, ki je sicer prispeval k njeni popularizaciji, toda hkrati je opozoril na mestoma neustrezen način prevajanja, ki je grešil v dvojem: posamezni slovnični termini so se prevajali s sodobnimi, ki imajo drug pomen, ali pa so se termini dobesedno prevajali glede na pomen $\mathrm{v}$ priročnem latinskem slovarju.

$\mathrm{Za}$ temo tega prispevka, ki izhaja iz imenovanega prevoda Bohoričeve slovnice, sta zlasti pomembni opombi v zvezi s prevodom besede etymologia, ki ni oblikoslovje, ampak oblikoslovno in besedotvorno pregibanje besed ter figura, ki ni podoba, ampak pomeni 'stopnja tvorjenosti' (Ahačič 2007: 79).

2.0 Glede na predstavljeno sta izhodiščna vidika pri predstavitvi Bohoričevega besedotvorja $\mathrm{v}$ tem prispevku dva: (1) vidik opazovanja na časovni osi ponuja možnost vrednotenja $\mathrm{v}$ slovnici zajetih besedotvornih kategorij s stališča sodobnega besedotvorja slovenskega jezika; (2) vidik zajetega besedotvornega gradiva v slovnici pa omogoča opazovanje dvojega, tj. Bohoričevo neposredno navajanje besedotvornih prvin $\mathrm{v}$ za to predvidenih poglavjih in posredno navajanje besedotvornih prvin zunaj njih.

2.1 Bohoričeva slovnica, kot je bilo že večkrat poudarjeno, sistematično vključuje besedotvorje v poglavju o imenih (samostalniki in pridevniki), glagolih in prislovih (Toporišič 1987: 44, 97, 157). Prvo imenuje figura (stopnja tvorjenosti/podoba), ${ }^{2}$ ki zajema kategorije: simplex - composita - decomposita, ponazorjeno s primeri za vsako besedno vrsto (pravizhen - nepravizhen nepravizhnoft; sekam - nafekam, perfekam - ne-prepovedujem $(<n e+$ prepovedujem < pre- 'ante' + povedujem < pogostostnik od povejm); davnaj, modru - zhesdan - nemodru. Drugo imenuje species (vrsta/vrstnost), prav tako za vse tri besedne vrste navaja kategoriji primitiva - derivativa, ki bosta s primeri podrobneje predstavljeni v nadaljevanju.

2.1.1 Bohorič pri posameznih besednih vrstah v poglavju Species predstavi več obrazil in besedotvornopomenskih kategorij.

V poglavju imena (nomina) Bohorič druži samostalnike, pridevnike in števnike. Z vidika tvorjenosti in netvorjenosti (Toporišič 1987: 67-76) pa poda zgled le za samostalnik: kojn (primitivum) in kojnzhik (dervativum). Pet pomenskih skupin povzema po Melanchtonu, povsem njegov dodatek so števniki (Ahačič 2007: 132).

1. Patronymica (očetna imena/očetna imena) vključuje obrazila za izsamostalniške pridevnike a) -ski (Blagajfki < grof Blagaja, tako še: Srinfki, Slujnfki, Mudrufki) in -čki (Tershazhki); b) opozori tudi na možnost ohranjanja nemškega končaja -er (Lamberger, Aurfperger); c) le-ta se postopno lahko podomači v -ar (Lambergar, Auerfpergar, Shrajar, Wernekar); č) ali

\footnotetext{
${ }^{2}$ V oklepaju sta zaporedno navedena prevoda Ahačiča (2007) in Toporišiča (1987).
} 
pa se tudi nemški besedi dodaja -zhizh (Lambergarzhizh, Auerfpergarzhizh, Shajrarzhizh, Wernekarzhizh) za razliko od Hrvatov, ki tu pogosteje dodajajo - -ki (Lambergarfki, Auerfpergarski, Shayrarfki, Wernekarfki itd); d) sočasno prikaže tudi danes imenovano tvorbo feminativov, tj. ženskospolskih ustreznic k moškim oblikam (Lambergar > Lambergarica); e) domovinskost zaznamujejo prav tako manjšalnice na -zhizh (Lublanzhizh, Kamenzhizh), ženska imena pa zadnji -zh spremenijo v -za (Lublanzhiza) ali pa oba zadnja zloga odpahnejo in delajo iz moške oblike Lublanzhizh žensko > Lublanfhiza, KamenShiza.

2. Possessiva (svojilna imena/svojilniki) so predstavljeni le z moškospolskim obrazilom -ov, -ova, -ovu (Shajrerjou) za vse tri spole, spregledano pa je, da je isto obrazilo tvorno tudi za srednji spol, medtem ko ženskospolsko tvorbeno obrazilo -in sploh ni omenjeno.

3. Diminutiva (pomanjševalnice/manjšalnice) predstavi z vidika spolov po obrazilih, vendar tako, da ob moških navaja hkrati tudi ženska za konkretne primere, čeprav nato žensko- in srednjespolska obrazila izpostavi posebej. Pri moškem spolu tako navaja -izh, -izhik, -iz, -ez, ${ }^{3}-i k,-i z h$ : krajl > krajlizh, krailizhik, mosh > moshiz, log > loszhiz, lok >lozhiz, ftol > ftoliz; nenavaden je primer $s o b>s o b e z$, ki je uvrščen med primere $\mathrm{z}-i z$, čeprav gre za -ez; navede tudi primere na -ik: Bob > Bobik, lon >lonik, Rak>Rakik in -izh: Lonz > Lonzhizh, Tat > tatizh; za ženskega -iza, -ka: krajl > krajlizhiza ali

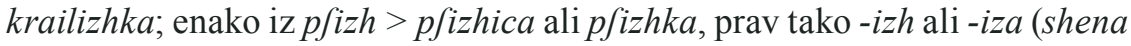
$>$ shenizh in sheniza; enako dekliza $>$ deklizh ali deklizhiza in pri srednjem spolu -ze: tele > teleze, peru > perze, dete $>$ deteze.

4. Pri kategoriji denominativa (imena iz imen/izimenke) navaja več podskupin: a) materiam (snov/snov): -en (za lat. besede na -eus): Shelesen; lat. besede na -atus pa razloži besednozvezno Shelesom oblit ali okovan; b) habitum (zunanjost/odevalo): prva dva primera sta prav tako besednozvezna s'plafhem oblezhen, s'vufhefmi obdilen, tvorbeno ustrezen je zgled na -at (rogat), besedotvorno ne ravno posrečen primer v tej skupini je pofhten; c) cupiditatem (željo/željnost): -en: vinen, z besednozvezno izrazitvijo v'vinu v'dan in kir rad punte sazhejnja; č) copiam (obilje/obilnost): -it, -én, -n, -en, -an: kamenit, voden, mozharn, pameten, pian; d) active significantia (tvornost/tvorno zaznamujoče): -iv: vuzhliv, Skarbliv; passivam habentia significationem (trpnost/trpni pomen zaznamujoče): -iv: nenavidliv, fovrashliv; loca arborum (mesta $\mathrm{z}$ drevjem/mesta drevja): -je, -ifhzhe: hraftje, verbje, verbifhzhe; receptacula rerum (posode in zbirališča/vsebovalniki stvari): -ica: perniza.

5. Med izimenske besede šteje tudi števnike, ki so povsem Bohoričev dodatek (Ahačič 2007: 132). Zanimiva je njegova metaforična razlaga glavnih števnikov (cardinalia) od 1-9 kot palcev, členki so mu desetice, zloženci pa števniki, nastali iz prstov in členkov. Prvi izmed takih zložencev je edennajft. Tvorbena je torej razlaga zložencev z -najst in desetic (dvajfset, tridefet,

\footnotetext{
${ }^{3}$ Tega obrazila ne izpostavi, a zanj navaja primer sobez.
} 
Shtirideset, petdefet ...). Posebej opozarja na to, da prsti stoje pred členki in samo prsti se sklanjajo, preostali del pa ostaja nesklonljiv.

$\mathrm{Z}$ vidika sodobnega besedotvorja je tudi Bohoričeva predstavitev vrstilnih (ordinalia) in množilnih (multiplicata) števnikov tvorbeno vprašanje. Avtor v oblikoslovnem smislu pri prvih izpostavlja končnice $-i,-a,-u$, ki so hkrati tudi tvorbeni morfemi. Od pet dalje navaja, da se samoglasnik - $i$ spremeni v -eri, -era, -eru. Tu gre z vidika sinhronije za kategorijo ločilnih števnikov, ki pa jih očitno izenačuje z vrstilnimi, ker navaja, da je poleg oblike, npr. dvajfet $-i$ - a, -u, običajnejši dvajfeteri, dvajfetera, dvajfeteru. Navaja pa tudi še vrstilne števnike s stoticami, npr. 213., ki jih zapisuje narazen; dvejftu inu trinajfti $-a$, -u, -eri, -era, -eru ipd.

Med množilnimi števniki (multiplicata) navaja tip: ena guba, dvei gubei, pri čemer je guba toliko kot nemško fach ali falt. Zaradi pisanja narazen z vidika sinhronije ni tvorjenka. Podobno kot ne števniki teže/pomnožni števniki (ponderalia), npr. Jamo fhterti $-a-u$, ki so kombinacija vrstilnih števnikov $\mathrm{z}$ besedico famo pred njimi, ter delilni/porazdelitveni števniki (distributiva), npr. velej eden ali vfaki fusseb, v/selej dva v'kup, vfelej tri v'kup itd.

Prislovni števniki (adverbialia) se tvorijo tako, da se glavnim dodaja krat (kuliku krat): enkrat ali fart, dva krat, tri krat, štirikrat, pet krat. Razvidno je, da sta samo dva primera izmed tam naštetih trinajstih tudi zapisana skupaj. Med časovnimi števniki (temporis) navaja leta Jtar, dvej leti Jtar ... ali pet let dolgu, Sheft let dolgu, ki besedotvorno niso zanimivi, saj gre za besednozvezno obliko. Posebej pa izpostavi števnike na -er/-ak, npr. drajer, tretjak, zhetertak, ki so dejansko posamostaljeni.

Po tem vrivku o števnikih sledi razdelek izglagolska imena/izglagolja (verbalia), ki nadaljujejo prekinjeno tipologijo tvorjenk. Tukaj namreč obravnava izglagolske samostalniške tvorjenke, pospremljene s pravilom, da se pogosto tvorijo iz nedoločniških glagolov, npr. lubiti > lubesan; boleti > bolefan; pejti $>$ peifen, prav tako pejviz, peuka; iz piffati nastane pismu in pifar.

2.1.2 Tudi glagol (Toporišič 1987: 97) vključuje poglavje Species (vrsta/ podoba), v katerem so predstavljene besedotvorne lastnosti glagola. Glagole najprej deli na prvotne (gorim, svetim) in tvorjene, ki jih je več vrst:

1. Inchoativa (glagoli s pomenom začenjanja/začetni glagoli): sazhnem goreti.

2. Frequentativa (glagoli s pomenom ponavljanja/pogostostni glagoli): pres preftanka delam.

3. Meditativa seu desiderativa (glagoli z želelnim pomenom/premišljalni ali želelni glagoli): podajajo se z miflim ali shelim: miflim oli shelim brati.

4. Deminutiva (glagoli z manjšalnim pomenom/manjšalni glagoli), ki se tvorijo $\mathrm{z}$ besedico per- > perpevam ali pomalim pojem, pomalim frebam.

5. Imitativa (glagoli s pomenom posnemanja/posnemovalni glagoli): po ozhini shari ali Shegi delam. Tem pridružuje prav vse nedovršnike različnih glago-

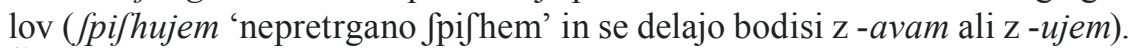
Če smo natančni, je besedotvornega tukaj mnogo manj kot pri imenih. Dobro je npr. njegovo opažanje manjšalnega pomena, ki ga glagolu lahko daje predpona 
pre-. Ta morfemska možnost je prezrta pri glagolih s pomenom začenjanja, saj se odloči za besednozvezni (sazhnem goreti) ne pa morda morfemski ustreznik (za-goreti). Ponavljalniki so tudi s stališča sinhronega vidika besedotvorna in oblikoslovna kategorija, ki se ji Bohorič najbolj približuje v skupini Imitativa. Le-ta pomenska skupina pa bi danes ustrezala glagolskim tvorjenkam, nastalim iz medmetov, npr. cmokati < delati cmok, čivkati < delati čiv ipd., kjer gre za dejanja, ki posnemajo zvočno oglašanje bitij, naprav in naravnih pojavov.

2.1.3 Posebno besedotvorno poglavje najdemo pri Bohoriču tudi pri prislovu (Toporišič 1987: 154). Prav slednje pa je bilo, razen pri Ahačiču (2007: 156), prezrto pri omenjenih razpravljalcih, ki so se tako ali drugače dotikali obravnave Bohoričevega besedotvorja.

Zanimivo je, da v uvodu Bohorič posebej izpostavi, da bo pri obravanavi prislovov sledil Latincem (Toporišič 1987: 178). Njegova besedotvorna opažanja, pa so mnogo boljša kot pri glagolu. Tako navaja prvotne (netvorjene) prislove (danes) in tvorjene, ki jih razporedi v več skupin:

1. A nomine (iz imena/izimenski prislovi): $k$ 'vezheri $<$ vezher, modru $<$ moder.

2. A pronomine (iz zaimka/izzaimenski prislovi: lefim, letja.

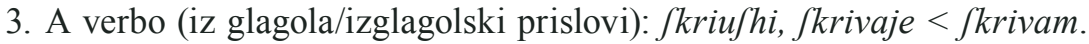

4. A prepositione (iz predloga/izpredložni prislovi): supernu < super 'proti'.

Slednji primer je dejansko drugostopenjska prislovna tvorjenka, nastala iz pridevnika, ki je tvorjen iz predloga (super > supern > supernu).

$\mathrm{V}$ nadaljevanju navaja štiriintridesetih pomenskih skupin prislovov, ki jih tukaj ne bomo naštevali. Včasih so med njimi s sinhronega vidika tudi členki (zilu, le), medmeti (hojfha), povedkovniki (vfhezh), kar ni nič posebnega, saj so členki postali samostojna besedna vrsta zelo pozno (Toporišič 1991: 3-16).

2.2 Zunaj teh za besedotvorje predvidenih poglavij pa se najde še marsikaj besedotvorno zanimivega.

2.2.1 V okviru t. i. imenskih vrst najdemo podrobnejše navajanje stopnjevanja pridevnika in prislova (Toporišič 1987: 158), ki se tudi še danes predstavlja kot oblikoslovno-besedotvorna kategorija modificiranih izpeljank (primerniki) in sestavljenk (presežniki):

1. Pridevnik: -fhi: ta bulfhi; nar-: ta nar bulfhi;

2. Prislovi iz pridevnih imen se stopnjujejo po vzorcu: Mozhnu - mozhne $h i$ ali vezh mozhnu - nar mozhne Shi ali vifoku mozhnu, torej podobno kot pridevniki srednjega spola. Hkrati pa se tako stopnjujejo tudi prvotni prislovi, ki se lahko krepijo s krčenjem: zheftu - zhejfhe ali zhejftefhi - gar zheftu. Iz česar se lepo vidi, da je opazil obrazilno in opisno stopnjevnje, hkrati pa tudi daljšo in krajšo obliko (čěšc (ejš)e).

2.2.2 V poglavju O sklanjanju zlaganj (Toporišič 1987: 78) se lepo vidi, da termin zlaganje pokriva tako besedno zvezo kot tvorjenko, saj navaja:

1. Zlaganje (besedno zvezo) iz dveh glavnih sklonov, ki se sklanja v obeh delih: hifni malik, tiga hifniga malika.

2. Zlaganje (tvorjenka iz glavnega in stranskega sklona): famorogazh, tiga Samorogazha. 
3. Zlaganje (v bistvu skupaj pisana besedna zveza iz dveh stranskih sklonov) pa je nesklonljiva: polmosha. Dejansko gre za zvezo pol moža, ko je zaradi količinskega izraza samostalnik v rodilniku, tvorjenka pa je dejansko polmož $-a,-u \ldots$, sklonljiva povsem običajno.

2.2.3 V okviru glagola so posredno zajete še naslednje besedotvorne kategorije izglagolskih tvorjenk:

1. Deležje na -ozh: delajozh, pifhejoč, lubijozh.

2. Deležnik na -zh: delajozhi $-a-e$, pifhejoč $-a-e$.

3. Glagolnik na -nje: delanje, pifanje, lublenje.

4. Trpni deležniki na -an, -en: Jekan, pezhen.

\section{Sklep}

Bohoričeva slovnica slovenskega jezika predstavlja pomemben slovničarski dosežek, saj se po času nastanka in po zgradbi suvereno umešča med sočasne evropske latinsko pisane slovnice ljudskih jezikov. Upoštevaje dejstvo, da je bil namen takih slovnic v prvi vrsti dokazovanje, da slovnični red in pravila tako kot latinščina premorejo tudi ljudski jeziki, kaže na Bohoričevo spretno dokazovanje podobnosti, a tudi samosvojosti slovenskega jezika. Slednje je pogosteje prišlo do izraza prav pri izvirnem navajanju zgledov za različne tipe tvorjenk.

S stališča sodobnega slovenskega besedotvorja je opazil nekaj najtipičnejših besedotvornopomenskih kategorij pri samostalniku (manjšalnice, tvorba feminativov tako z dodajalnim (Lubalnzhizh $>$ Lublanzhiza) ali zamenjevalnim tipom (Lubalnzhizh > Lublanfhiza) in možnost izglagolsko tvorjenih samostalnikov), pri pridevniku (izimenske vrstne na -ski, svojilne na -ov in prav tako izglagolske) ter pri prislovu njihovo izimensko (modru), izzaimensko (lefim), izglagolsko ( (kriufhi, Jkrivaje) in izpredložno tvorbo (supernu). Pri večini primerov tvorjenk je celo povsem izviren. Izpostavil je nekatera tipična samostalniška (-izh, -izhik, -iz, -ez, -ik, -izh; -iza, -ka; -ze), pridevniška (-ski, -en, $-a t)$ in prislovna tvorbena obrazila $\left(-u \int h i,-a j e,-u\right)$, rodna še danes. S primerom je ponazoril manj tipično družljivost ženskospolske podstave $\mathrm{z}$ obrazilom, običajnejšim za moškospolske podstave, in tipično spolsko usklajenost obojega (shena $>$ shenizh in sheniza), opazil je možnost istokorenskih tvorjenk (pejti $>$ peifen, pejviz, peuka ali iz piffati nastane pismu in pifar) in s tem posredno nakazal besedno družino. Kadar mu je bilo za latinsko besedo težko najti ustrezno slovensko tvorjenko, jo je pogosto opisal, opis pa je ponekod praktično skladenjskopodstavni (kir rad punte sazhejnja).

Bohoriču je kljub latinski jezikovnosistemski predlogi treba priznati izjemno jezikovno razgledanost in sposobnost kategoriziranja tudi vsega besedotvornega, kar je bilo v času nastanka slovnice živa in dovolj opazna prvina slovenskega govorjenega in/ali pisanega jezika 16. stoletja. 


\section{VIRI IN LITERATURA}

Maks PLETERŠNIK, 1894-1895: Slovensko-nemški slovar I (A-O, 1894), II (P-Ž, 1895). Ljubljana.

Jože TOPORIŠIČ, 1987: Adam Bohorizh: Arcticae horulae succisivae. Zimske urice proste. Maribor: Založba Obzorja Maribor.

Kozma AHAČIČ, 2007: Zgodovina misli o jeziku in književnosti na Slovenskem: Protestantizem. Ljubljana: Založba ZRC SAZU.

Igor GRDINA, 1999: Od Brižinskih spomenikov do razsvetljenstva. Maribor: Založba Obzorja.

Rudolf KOLARIČ, 1971: Die Sprache in Adam Bohoričs Arcticae horulae. Adam Bohorič Arcticae horulae: Die erste Grammatik der slowenischen Sprache. II. Teil: Untersuchungen. München: Rudolf Trofenik, 29-82.

Martina OROŽEN, 1971: Začetki slovenske jezikoslovne misli. Jezik in slovstvo (16/7), 193-200.

Irena STRAMLJIČ BREZNIK, 1996: Besedotvorje in njegovo izrazje v slovensko pisanih slovnicah 19. stoletja. C̆asopis za zgodovino in narodopisje. 32/2, 248-261.

Jože TOPORIŠIČ, 1984: Oblikoslovje v Bohoričevih Zimskih uricah. 20. seminar slovenskega jezika, literature in kulture, 189-222.

--, Členki in njihovi stavčni ustrezniki. 27. seminar slovenskega jezika, literature in kulture. Ljubljana, 3-16.

- -, 2000: Slovenska slovnica. Četrta, prenovljena in razširjena izdaja. Maribor: Založba Obzorja.

\section{SUMMARY}

The first Slovene Grammar Book, written by Adam Bohorič (1584), has been the subject of numerous accurate treatments in terms of its origin as well as its sociolinguistic and grammatical points of view, with even greater interest in morphology and syntax.

This article discusses word-formation and assesses it according to contemporary theoretical values.

Bohorič noticed some typical meaningful word-forming categories with respect to nouns (diminutives, forming feminines by additional (Lubalnzhizh $>$ Lublanzhiza) or exchangeable type (Lubalnzhizh > Lublanfhiza) and the possibility of making nouns from verbs), adjectives (pronominal denoting type / kind on -ski, possessive on -ov and adjectival made from verbs), and adverbs originating in nouns (modru), pronouns (lefim), verbs (Jkriufhi, Jkrivaje) and propositions (supernu). In most cases, his argumentation is highly original. 
He stressed some endings typical of nouns (-izh, -izhik, -iz, -ez, -ik, -izh; -iza, -ka; $-z e)$, adjectives $(-s k i,-e n,-a t)$ and adverbs $\left(-u \int h i,-a j e,-u\right)$, which are in use even today.

Bohorič illustrated with examples less typical associations of feminine bases with more typical endings for masculine bases and typical gender adjustments of both (shena $>$ shenizh in sheniza). He noticed the possibility of derivatives from the same root (pejti > peifen, pejviz, peuka ali piffati > pismu, pifar) and indirectly noticed word-families. When he encountered problems with adequate Slovene derivational forms from Latin, he described them and the description was practically based on syntax (kir rad punte sazhejnja). 